Uşak Üniversitesi Sosyal Bilimler Dergisi

$2014,7 / 4$

\title{
Çokkültürlü Eğitim Yaklaşımının Etkililik Düzeyi: Bir Meta-Analiz Çalışması
}

\section{Özet}

\author{
Rafet GÜNAY* \\ Yeliz KAYA** \\ Hasan AYDIN ${ }^{* * *}$
}

Bu çalışmayla, dünyada çokkültürlü eğitim ile ilgili yapılmış birbirinden bağımsız çalışmalardan elde edilen sonuçların birleştirilmesi amaçlanmıştır. Araştırmada cevabı aranan soru: "Çokkültürlü eğitim yaklaşımı, öğrencilerin akademik başarısını etkilemekte midir?" şeklinde ifade edilmiştir. Araştırmada nicel verilerin bir araya getirilerek yorumlanması meta-analiz yöntemiyle sağlanmıştır. Meta-analiz yöntemi, birbirinden bağımsız araştırmaların nicel verilerinin bir araya getirilerek nicel verilerinin istatistiksel yorumlanması ve sonuçların sentezlenmesi sürecidir. Bu bağlamda, alan yazın taraması 1994-2013 yılları arasında yapılmış çokkültürlü eğitim yaklaşımının öğrencilerin akademik başarısı üzerindeki etkisini araştıran çeşitli ülkelerde İngilizce yazılmış çalışmalar meta-analiz araştırmasına dâhil edilmiştir. Meta-analize dâhil edilecek araştırmaların hangi kriterlere göre bir araya getireceği belli ölçütler çerçevesinde gerçekleştirilmiştir. Bu ölçütler sonucunda araştırmaya 17 deneysel çalışmanın eklenmesine karar verilmiştir. Araştırma sonucunda, çokkültürlü eğitim yaklaşımının akademik başarıya orta düzeyde olumlu etkisinin olduğu bulunmuştur. Bu etkililik düzeyinin çalışmanın yapıldığı yıllara göre, öğrenim düzeyine göre ve ülkelere göre farklılık gösterdiği; çalışmanın yapıldığı bölüm ve araştırma sürelerine göre farklılık göstermediği sonucuna varılmıştır.

Anahtar Kelimeler: Çokkültürlü eğitim, Meta-analiz Yöntemi, Akademik Başarı, Etki Büyüklüğü.

\footnotetext{
* Doktora Öğrencisi, Yıldız Teknik Üniversitesi, Eğitim Fakültesi, Eğitim Bilimleri Bölümü, Eğitim Programları v e Öğretim, gunay.rafet@gmail.com

${ }^{* *}$ Doktora Öğrencisi, Yıldız Teknik Üniversitesi, Eğitim Fakültesi, Eğitim Bilimleri Bölümü, Eğitim Programları v e Öğretim,yelizkizmazer@gmail.com

${ }^{* * *}$ Yrd. Doç. Dr. Yıldız Teknik Üniversitesi, Eğitim Fakültesi, Eğitim Bilimleri, Bölümü, Eğitim Programları v e Öğretim, aydinh@yildiz.edu.tr
} 


\section{The Effectiveness Level of Multicultural Education: A Meta-Analysis}

$$
\text { Study }
$$

\section{Abstract}

The purpose of this study is to investigate the results obtained in independent studies that aiming to determine the effectiveness of multicultural education in the world. The main question in this study was: “Does Multicultural education approach improve students' academic achievements?". To interpret a put together data, the meta-analysis method was employed. Meta-analysis method was the process in order to statistically analyze the quantitative data collected in independent and multiple studies carried out on similar topics, and to reach a general judgment regarding the results of these studies. In this respect, following the literature research, studies which investigated the effectiveness of multicultural education on students' academic achievement between the years 1994-2013 met the inclusion criteria, were reported in English and were included in the meta-analytical research. Based on these criteria, it were decided to include 17 experimental studies in the meta-analysis. It revealed that multicultural education approach had a positive but medium effect on students' academic achievement. The results od this study indicated that were a significant difference bewteen education level and the countries situation level. In addition, it was determined that there is no difference in any effect sizes in terms of course types and process time of study.

Key Words: Multicultural Education, Meta-Analysis Method, Academic Achievement, Effect Size.

\section{Giriş}

Çokkültürlü eğitim, yıllardır eğitim dünyasında konuşulan tartışmalı konulardan birisidir. Çokkültürlü eğitim 1970'lerde telaffuz edilmesine rağmen, kökleri çok daha eskilere (1880'li yıllar), AfroAmerikalıların kendi kültürlerini çocuklarına öğretme ve hak arayışı mücadelelerine kadar gitmektedir (Banks, 1993). Diğer taraftan, yakın geçmişe kadar çokkültürlü eğitim dendiğinde akla, eritme potası (melting pot) denen asimilasyon çalışmaları gelmekteydi. Bu bakış açısına göre farklı kültürel ve etnik gruplar kendi aidiyet, dil, cinsiyet, kültür, din gibi değerleri bir tarafa bırakıp bulundukları ülkenin baskın kültürünü benimsemeleri gerekmekteydi (Ameny-Dixon, 2004). Adil ve demokratik eğitim arayışının 
öne çıkmasıyla, çokkültürlü eğitim küresel gündeme oturmuştur (Bennett, 2003).

Çokkültürlü eğitim, demokratik değerleri ve amaçları, kültürel çoğulculuğu, sosyal adaleti ve öğrencilerin sosyal, kişisel ve entelektüel gelişimlerini temel alan eğitimdir (Nieto \& Bode,2011). Günümüz toplumlarının içinde bulunduğu sosyolojik yapı, resmi veya kültürel kurallara göre farklı kimlikleri bir arada tutsa da, ırkçılığı, kültürel dejenerasyonu ve ahlaki değerleri ayakta tutamamaktadır (Bucher, 2009; Nieto, 2010). Daha yakın zamanda, İspanya'da 2006 yılında Etoo'ya ve 2014'te Dani Alves'e atılan muz dolayısıyla rrkçılık kendini futbol sahalarında göstermeye devam etmiştir (Zachary, 2014). Uluslararası maçlar öncesinde "rrkçılığa hayır" afişlerinin karşı futbolcular tarafından tüm seyircilere gösterilmesi bu konuda atılan adımlardan birisidir. Bu sebeple ırkçı davranışların üstesinden gelebilmek için çokkültürlü eğitimin çok önemli bir unsur olduğu söylenebilir.

Banks'e göre (2008) çokkültürlü eğitimi gerekli kılan şeyler: (i) etnik çoğulculuk, (ii) farklı kültür ve etnik gruplar hakkında yanlış bilgilere sahip olma, (iii) etnik ve kültürel gruplar hakkında edinilen bilgilerin ve inanışların negatif yönde olması farklı gruplar için fırsatların sınırlanması olarak karşımıza çıkmaktadır. Çokkültürlü eğitim, çoğulculuk fikrini tüm dünyaya öğretmesi, öğrencilerin farklı kültürlerle etkin bir şekilde iletişime geçebilmelerini sağlaması, eşitlikçi, adaletli ve çoğulcu bir toplumun harekete geçmesini sağlamaktadır (Gay,2004; NAME, 2012; Wilson, 2012).

Çokkültürlü eğitim, bazı teorisyenler tarafından eğitimin kalitesini arttıran bir uygulama olarak görülmektedir (Gay, 2004). Farklı gruptan insanların bir arada yaşadığı toplumlarda herkesin memnun olacağ 1 ve huzur içinde yaşayacağı bir sistem oluşturmak kaçınılmazdır. Bu konuda en önemli görev de eğitime ve öğretmenlere düşmektedir (Banks \& Banks, 2001). Çokkültürlü eğitim, tüm öğrenciler için eşit şartlarda, kişilerin birbirine saygı duyacağı bir eğitim ortamı oluşturmayı amaçlaması dolayısıyla kabul görmektedir. Asıl itirazlar çokkültürlü eğitim uygulamalarına yapılmaktadır (Başbay ve Kağnıcı, 2011).Çokkültürlü eğitimin önünde farklı bakış açlarından kaynaklanan sorunlar engel olarak durmaktadır. Bunlar, yetişmiş öğretmen, program, ders kitabı kaynaklı olabilir (Gay, 2004). Bu sorunların çözümüyle, öğrencilerde sosyal adaletin, eşitliğin, demokratik değerlerin, farklılığın, kültürel çoğulculuğun ve akademik başarının arttığı gözlenmiş olacaktır. Ayrıca, çokkültürlü eğitim: (i) tüm insanlarda bilişsel ve duyuşsal gelişimin artmasına, (ii) yaratıcı problem çözme yeteneğinin artmasına, (iii) sevgi, saygı ve hoşgörünün başarılmasıyla pozitif ilişkiler kurmaya, (iv) kültürel farklılıktan dolayı geçmiş kalıplar ve 
önyargıları azaltmasına, (v) farklı zengin kültürleri bir arada bulundurmasıyla sosyal hayatı yenilemeye yardımcı olmaktadır (Aydın; 2013; Banks, 2008; Bennett, 2011; Clark \& Gorski, 2002; Gay, 2004; Johnson \& Johnson, 2002).

Çokkültürlü eğitim ile ilgili yapılmış araştırmalar, çokkültürlülük ve eğitime yansımaları hakkında bize bilgi vermektedir. Bu çalışmanın amacı, dünyada çokkültürlü eğitim ile ilgili yapılmış birbirinden bağımsız çalışmalardan elde edilen sonuçların birleştirilerek tek bir resmi ortaya koymaktır. Bu amaçla elde edilen çalışmalar sadece deneysel çalışmalardan oluşmakta ve 17 çalışma ile sınırlandırılmıştır. Eldeki 17 bağımsız araştırmanın nicel verilerinin bir araya getirilmesi ve analiz edilerek sentezlenmesi süreci meta-analiz yöntemi ile sağlanmıştır.

\section{Meta-Analiz Yöntemi}

Meta-analiz, çalışma sonuçlarını birleştirmek için kullanılan bir nicel yöntemdir (Petticrew, \& Roberts, 2006). Bilim adamları ve akademisyenler, sosyal ve davranış bilimleri alanında tek çalışma ve deneyin araştırmada sorulan soruya kesinlikle doğru cevabı vermediğini söylemektedir (Hedges \& Olkin, 2013). Dolayısıyla, birçok bilim dalında para, zaman, eleman ve uzman araştırmacı yetersizliğinden dolayı, evreni temsil eden yüksek örneklemler üzerinde çalışmalar yapmak her zaman mümkün olmamaktadır. $\mathrm{Bu}$ nedenle çalışmalar çoğunlukla küçük örneklemler üzerinde, farklı zamanlarda yürütülmektedir (Wolf, 1986). Alanyazın incelendiğinde, bir konuya ilişkin farklı örneklemlerde yürütülmüş benzer pek çok araştırma bulunduğu ve belirli ölçütler esas alınarak bu araştırmalar toplanıp incelendiğinde birbirinden tutarsız sonuçlar verebildiği görülmektedir (Smith, Constantine, Dunn, Dinehart \& Montoya, 2006).

Meta-analizde, farklı çalışmalara ait standartlaştırılmış etki büyüklükleri, korelasyon katsayıları veya $\mathrm{p}$ değerleri gibi niceliklerin özet istatistiklerinin bir analizi yapılmaktadır (Hedges ve Olkin, 1985). Etki büyüklüğü ise bir araştırmadaki etkinin veya bir olgunun toplumda meydana gelme sıklığı olarak tanımlanmaktadır (Cohen, 2013). Metaanalizin diğer alanyazın tarama yöntemlerinden farkı, araştırma bulgularının bir araya getirilip bütünleştirilmesinde ve analizinde istatistiksel yöntemlerin kullanılmasıdır (Glass, McGaw \& Smith, 2012). Hedges ve Olkin'e (1985) göre, meta-analiz yönteminin temel amaçları: 
1. Küçük örneklemlerde yapılmış çalışmaları birleştirerek toplam örneklem genişliğini büyütmek, bu sayede parametre tahminlerinin kesinliğini ve gücünü arttırmak,

2. Alanyazınde benzer araştırmaların sonuçlarının tutarsızlıklarını değerlendirmek ve kaynaklarını araştırmak,

3. Yapılan araştırmalarda düşünülmeyen ancak etkisi olduğu varsayılan değişkenleri incelemek,

4. İleride yapılacak araştırmalara ve alınacak kararlara yardımcı olmak,

5. Elde edilen bulgularla ileride incelenmesi gereken yeni araştırma konuları ortaya çıkarmak

olarak sıralamaktadır.

\section{Yöntem}

Bu çalışmada, sistematik sentezleme olarak kabul edilen meta-analiz yöntemi kullanılmıştır. Meta-analiz, birbirinden bağımsız çalışmaların nicel bulgularina dayanılarak yapilan istatistiksel sentezleme ve yorumlama olarak tanımlanmaktadır (Ellis, 2012; Petticrew \& Roberts, 2006).

\section{Verilerin Toplanması ve Alanyazın Taraması}

Çokkültürlü eğitimin öğrencilerin tutum ve düşünceleri üzerindeki etkisini tespit etmek amacıyla, çokkültürlü eğitimle ilgili olarak 1994-2013 yılları arasında yapılmış olan araştırmalar çalışma kapsamında incelenmiştir. Araştırmaların 1992 yılından itibaren Amerika dışında da yürütülmesi sebebiyle eldeki çalışma bu yıllar arası ile sınırlandırılmıştır. Araştırmaya hangi çalışmaların dâhil edileceğine karar vermede aşağıdaki ölçütler kullanılmıştır:

1. 1994 ile 2013 yılları arasında Dünya'da çokkültürlü eğitim ile ilgili yayınlanmış çalışmaların etkililik düzeyini belirlemek için eldeki çalışmalar analiz edilmiştir.

2. İlgili çalışmalar, ulaşılabilen doktora, yüksek lisans tezleri ve makalelerden oluşmaktadır.

3. Eldeki araştırmaya deney ve kontrol grubu bulunan çalışmalar dâhil edilmiştir. Deney grubuna çokkültürlü eğitim uygulanan, kontrol grubunda ise çokkültürlü eğitim uygulanmayan çalışmalar dâhil edilmiştir.

4. Birden fazla deney grubu bulunan çalışmalarda sadece çokkültürlü eğitimin uygulandığı grup deney grubu olarak kabul edilmiştir.

5. Etki büyüklerinin hesaplanabilmesi için aritmetik ortalama, standart sapma ve katılımcı sayıları verilmeyen çalışmalara yer verilmemiştir. 
6. Birden fazla test uygulanan çalışmalarda, rastgele bir testin verileri dikkate alınarak analiz edilmiştir.

7. Yalnızca İngilizce yayınlanmış ve elektronik ortamda taranan çalışmalar analize dahil edilmiştir.

Veri toplamak amaciyla arama motorlarına "multicultural education ABD control group", "multicultural education ABD quasi experimental", "multicultural education Canada control group", "multicultural education Canada quasi experimental" gibi anahtar kelimeler yazılarak makaleler, yüksek lisans ve doktora tezleri taranmıştır. Bu amaçla yaklaşık 300 çalışma taranmış fakat bazılarının nitel çalışma olması, bazı çalışmalarda da kontrol grubu bulunmaması dolayıyla ilk etapta 62 çalışmanın değerlendirilmeye alınabileceği belirlenmiştir. Sonrasında yapılan incelemelerde, etki büyüklükleri için istenen istatistiki verilere sahip olmamasından dolayı bazı çalışmaların da araştırmaya dahil edilemeyeceğine karar verilmiştir. Sonuç olarak ölçütlere uygun deneysel ve yarı deneysel 17 adet çalışmasının (16 makale, 1 doktora tezi) örneklemini oluşturmaktadır.

\section{Verilerin Kodlanması}

Tüm araştırmalar bir Microsoft Excel dosyası üzerinde, yazar adı, çalışma yıll, yayın türü, veri toplama aracı, araştırmanın yapıldığı ülke, katılımcı özellikleri, uygulama süresi, deney grubu sayısı, deney grubu aritmetik ortalama, deney grubu standart sapma, kontrol grubu sayısı, kontrol grubu aritmetik ortalama ve kontrol grubu standart sapma bilgileri olacak şekilde tasnif edilmiştir.

\section{Değişkenler}

Meta-analize dahil edilen çalışmalarda kullanılan, çokkültürlü eğitimin etkililiği ile ilgili etki büyüklükleri bağımlı değişken olarak tanımlanmıştır. Bağımsız değişken (Çalışma karakteristikleri) olarak çalışma yılı, araştırmanın yapıldığı ülke, katılımcı özellikleri, uygulama süresi ve örneklem sayıları dikkate alınmıştır.

\section{Verilerin analizi}

Meta-analiz çalışmasında, nicel veriler aracılı̆̆ıyla etki büyüklükleri (effect size) hesaplanır. Bağımsız araştırmaların etki büyüklükleri kontrol edilerek model seçimi yapılır ve heterojenlik testi uygulanır. Verilerin analizinde ise işlem etkisi meta-analiz yöntemi uygulanır. Bu yöntemde $d=$ $\left(\mathrm{Xe}-\mathrm{Xc}_{\mathrm{c}}\right) / \mathrm{SD}$ formülü ile gösterilen deney ve kontrol gruplarının aritmetik 
ortalamaları arasındaki fark hesaplanır ve toplam standart sapmaya bölünür(Hunter \& Schmidt, 2004).

İşlem Etkisi meta-analiz yönteminde, " $\mathrm{d}$ " veya "g" gibi standartlaştırılmış etki büyüklüğü değerleri kullanılır. Bu araştırmada ise etki büyüklügünü hesaplamak için "Hedges' d" kullanılmıştır. Meta-analiz sürecinde, etki büyüklerinin homojen dağılımı sonucu sabit etkiler modeli, heterojen dağılımı sonucu ise rastgele etki modeli kullanılmaktadır (Ellis, 2010). Bu araştırmada analizlerin yapılabilmesi için, Comprehensive Meta Analysis ve MetaWin İstatistik programlarından yararlanılmıştır.

\section{Bulgular}

$\mathrm{Bu}$ araştırmada 17 çalışmanın örneklem sayısı, standart sapması ve aritmetik ortalamaları kullanılarak etki büyükleri hesaplanmıştır. 17 çalışmanın tamamında deney grubu 688, kontrol grubu 557 olmak üzere toplam 1245 öğrenci üzerinden veri toplanmıştır. Çalışmaların gerçekleştirildiği yıl, yapıldığı ülke, katılımcı özellikleri, uygulama süresi değişkenlerine göre frekans bilgileri Tablo 1'de gösterilmiştir. 
Tablo 1. Çalışmaların Değişkenlere Göre Frekans ve Yüzde Değerleri

\begin{tabular}{|c|c|c|c|c|c|}
\hline Değişken & Frekans & $\begin{array}{l}\text { Yüz } \\
\text { de( } \\
\%)\end{array}$ & Değişken & Frekans & $\begin{array}{l}\text { Yüzd } \\
\text { e (\%) }\end{array}$ \\
\hline \multicolumn{3}{|l|}{ Çalışma Yılı } & \multicolumn{3}{|c|}{ Çalışmanın Yapıldığ Ülke } \\
\hline 1994 & 1 & 5,9 & Avusturya & 1 & 5,9 \\
\hline 1998 & 1 & 5,9 & Güney Kore & 1 & 5,9 \\
\hline 2000 & 1 & 5,9 & Tayvan & 1 & 5,9 \\
\hline 2001 & 1 & 5,9 & Türkiye & 2 & 11,8 \\
\hline 2002 & 1 & 5,9 & Amerika & 12 & 70,6 \\
\hline 2003 & 1 & 5,9 & \multicolumn{3}{|c|}{ Uygulama Süresi } \\
\hline 2005 & 1 & 5,9 & 45-50 dakika & 1 & 5,9 \\
\hline 2008 & 1 & 5,9 & 4 saat & 1 & 5,9 \\
\hline 2010 & 2 & 11,8 & 3 ders & 1 & 5,9 \\
\hline 2011 & 3 & 17,7 & 2 hafta & 1 & 5,9 \\
\hline 2013 & 4 & 23,6 & 5 hafta & 2 & 11,8 \\
\hline \multicolumn{3}{|c|}{ Çalışmanın Uygulandığı Grup } & 8 hafta & 1 & 5,9 \\
\hline Tip & 1 & 5,9 & 12 ders & 1 & 5,9 \\
\hline Ticaret okulu & 1 & 5,9 & 1 dönem & 7 & 41,3 \\
\hline Eğitim fakültesi & 2 & 11,8 & $1 \mathrm{yll}$ & 1 & 5,9 \\
\hline Psikoloji & 5 & 29,5 & Belirlenemeyen & 1 & 5,9 \\
\hline Ana Sinifi & 1 & 5,9 & \multicolumn{3}{|c|}{ Öğrenim Düzeyi } \\
\hline Ortaokul & 2 & 11,8 & Ana Sinifi & 1 & 5,9 \\
\hline $\begin{array}{l}\text { Sosyal } \\
\text { Hizmetler }\end{array}$ & 1 & 5,9 & Ortaokul & 2 & 11,8 \\
\hline $\begin{array}{l}\text { Rehberlik } \\
\text { Bölümü }\end{array}$ & 2 & 11,8 & Lisans & 10 & 59 \\
\hline Belirlenemeyen & 1 & 5,9 & $\begin{array}{l}\text { Yüksek Lisans } \\
\text { Doktora } \\
\text { Belirlenemeyen }\end{array}$ & $\begin{array}{l}2 \\
1 \\
1\end{array}$ & $\begin{array}{l}11,8 \\
5,9 \\
5,9\end{array}$ \\
\hline
\end{tabular}

Araştırmaya dahil edilen çalışmaların büyük çoğunluğunun (\%53,1) 2010 yılı ve sonrasına ait olan çalışmalar olduğu görülmektedir. 2010 yılında $2(\% 11,8)$, 2011 yılında $3(\% 17,7)$ ve 1013 yılında 4 (\%23,6) çalışma yapılmıştır. Çalışmaların yapıldığı ülkelere göre dağılımına bakıldığında en çok çalışmanın 12 çalışmayla Amerika'da yapıldığı görülmektedir. Çalışmaların uygulanma sürelerine göre frekans ve yüzde değerlerine bakıldığında, en 
fazla çalışmanın $(\% 35,4) 1$ dönem uygulanan çalışmalar olduğu, bunu $(\% 11,8) 5$ hafta uygulanan çalışmaların izlediği görülmektedir. Çalışmanın uygulandığı bölümlere göre dağılımına bakıldığında en çok çalışmanın 5 çalışma $(\% 29,5)$ ile psikoloji bölümü öğrencileri ile yapıldığı, bunları 2'şer çalışma $(\% 11,8)$ ile eğitim fakültesi ve rehberlik bölümü öğrencilerinin izlediği görülmektedir. Çalışmaların öğrenim düzeyine göre frekans ve yüzde değerlerine bakıldığında, en fazla çalışmanın 10 (\%59) çalışma ile lisans öğrencileri ile yapıldığı, yüksek lisans öğrencileri ile 2 (\%11,8), ortaokul öğrencileriyle $2(\% 11,8)$, doktora öğrencileriyle 1 ve anasınıfı öğrencileriyle yapılan $1(\% 5,9)$ çalışmanın olduğu görülmektedir.

Diğer taraftan araştırmaya dâhil edilen çalışmalar standart hata ve varyans değerleriyle birlikte etki büyüklüğü ortak bir tabloda birleştirilmiştir. Şekil 1 meta-analize dahil edilen çalışmaların her birinin ayrı ayrı güven aralığını, etki büyüklüğünü ve toplam etki büyüklüğü üzerindeki ağırlı̆̆ı göstermektedir.
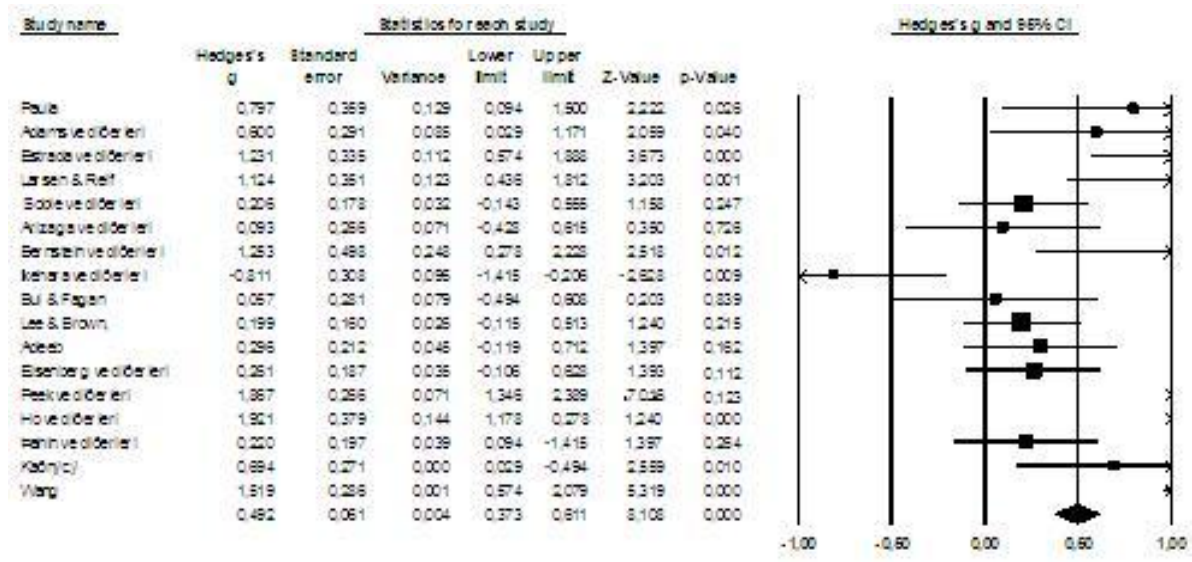

Şekil 1. Çalışmaların Etki Yönünü Gösteren İlk Meta-analiz Diyagramı (Forest Plot)

Şekil 1'de meta-analiz kapsamında ele alınan çalışmaların etki büyüklüklerinin verildiği meta-analiz diyagramı (forest plot) görülmektedir. Etki büyüklükleri kare ile tasvir edilmiş olup her karenin içinden yatay çizgiler ne kadar uzunsa güven aralığının o kadar geniş olduğunu göstermektedir. Oklar ise diyagrama sığmayan güven aralığını göstermektedir. Şekil 1'e göre en geniş güven aralı̆̆ Bui\&Fagan (2013) olarak görülmektedir. Ayrıca, araştırmada kullanılan 17 çalışmanın 16'sının 
pozitif etki büyüklüğüne sahip olduğu, 1 tanesinin negatif etki büyüklüğüne sahip olduğu görülmektedir. Etki büyüklüğünün pozitif olması etki büyüklügüün̈n deney grubu lehine olduğunu göstermektedir. Meta-analize dahil edilen çalışmaların homojen dağılım değeri, ortalama etki büyüklüğü ve güven aralığı Tablo 2'de gösterilmiştir.

Tablo 2. Meta-analize Dâhil Edilen Çalışmaların Etki Modellerine Göre Homojenlik Değerleri ve Etki Büyüklükleri

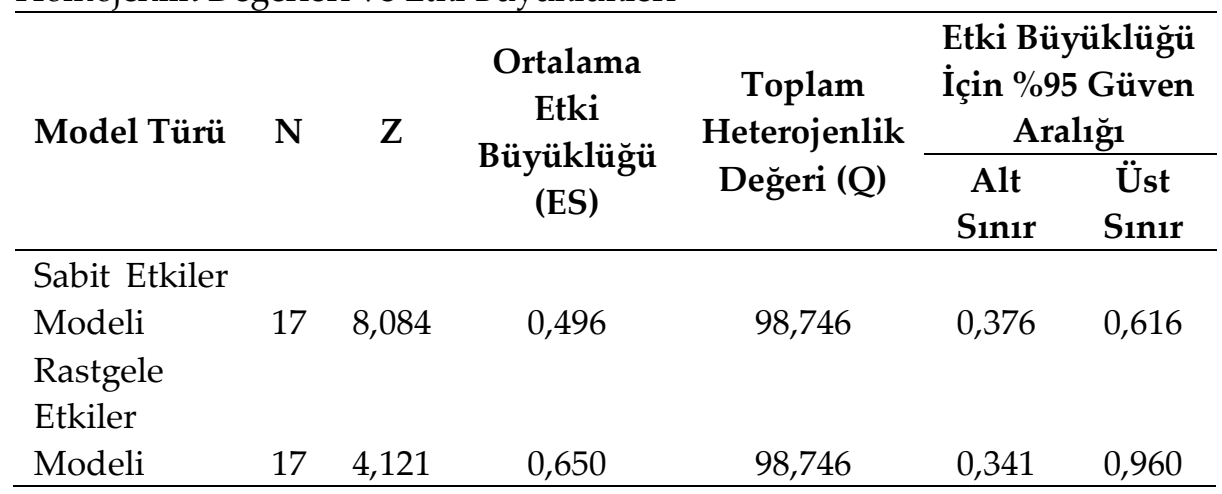

Çokkültürlü eğitimin akademik başarıya etkisinin sabit etkiler modelinde 0,496 etki büyüklüğü değeri ile pozitif yönde olduğu söylenebilir. Etki büyüklüğü değerlerinin pozitif çıkması bu boyutlardaki performansların etki büyüklüğü derecesince deney grubu lehine olduğunu göstermektedir. Eğer sonuç negatif çıkmış olsaydı etki büyüklüğü kontrol grubu lehine çıkmış olacaktı (Wolf, 1986, s.26). Homojenlik testi sonucunda Q istatistik değeri 98,746 olarak hesaplanmıştır. X2 tablosundan \%95 anlamlılık düzeyinde 16 serbestlik derecesi 83,797 bulunmuştur. Yani Q istatistiksel değeri $(98,746)$, ki-kare dağılımının kritik değerini $\left(x^{2}(0.95)=83,797\right)$ aştığı için çalışmaların dağılımı sabit etkiler modeline göre heterojen özellik göstermektedir. Q istatistik değeri sonucunda çalışmaların heterojen özellik göstermesi çalışmalara rastgele etkiler modeline uygun analiz yapılarak, örneklemin heterojenlikten kurtarılmak amaçlanır. Bu sebeple meta-analize dâhil edilen 17 çalışmadaki veriler rastgele etkiler modeline göre; 0,158 standart hata ve \%95'lik güven aralığının alt sınırı 0,341 ve üst sınırı 0,960 ile etki büyüklüğü değeri $E S=0,650$ olarak hesaplanmıştır. İstatistiksel anlamlılık amacıyla gerçekleştirilen z-testi sonucunda $z=4,121$ bulunmuştur. Dolayısıyla $\mathrm{p}=0.000$ ile analizin istatistiksel olarak anlamlı olduğu söylenebilir. 


\section{Çokkültürlü Eğitimin Çalışmanın Yapıldığı Yıllara Göre Etkililiğgi}

Çokkültürlü eğitimin etki büyüklüğünün çalışmanın yapıldığı yıla göre farklılaşıp farklılaşmadığını belirlemek için çalışmalar 2010, 2011 ve 2013 olmak üzere 3 gruba ayrılmıştır. Diğer yılların etki büyüklüğü için yeterli sayıda olmamasından dolayı Tablo 3'te yer verilmemiştir. Verilen 3 yılın analiz sonuçları Tablo 3'te gösterilmiştir.

Tablo 3. Çalışmaların Yapıldığı Yıllara Göre Homojenlik Değerleri ve Etki Büyüklükleri

\begin{tabular}{|c|c|c|c|c|c|}
\hline \multirow[t]{2}{*}{$\begin{array}{l}\text { Model } \\
\text { Türü }\end{array}$} & \multirow[t]{2}{*}{$\begin{array}{l}\text { Gruplar arası Etki } \\
\text { Büyüklüğgü }\left(Q_{B}\right)\end{array}$} & \multirow[t]{2}{*}{$\mathbf{N}$} & \multirow[t]{2}{*}{ ES } & \multicolumn{2}{|c|}{$\begin{array}{c}\text { Etki Büyüklüğü } \\
\text { İçin \%95 Güven } \\
\text { Aralığı }\end{array}$} \\
\hline & & & & Alt Sinır & Üst Sinır \\
\hline Yillar & 1,183 & & & & \\
\hline 2010 & & 2 & 0,299 & 0,010 & 0,589 \\
\hline 2011 & & 3 & 0,474 & 0,202 & 0,745 \\
\hline 2013 & & 4 & 0,500 & 0,281 & 0,720 \\
\hline
\end{tabular}

Tablo 3'e göre, çalışmaların yapıldığg yıllara göre en yüksek etki büyüklüğü 0,500 ile 2013 yılı, en düşük etki büyüklüğü ise 0,299 ile 2010 yllına aittir. Homojenlik testi sonucunda $Q$ istatistik değeri 1,183 olarak hesaplanmıştır. $X^{2}$ tablosundan $\% 95$ anlamlılık düzeyinde 2 serbestlik derecesi 76,323bulunmuştur. Yani $Q$ istatistiksel değeri $(1,183)$, ki-kare dağılımının kritik değerinden $\left(x^{2}(0.95)=76,323\right)$ küçük çıktığı için çalışmaların yıllara göre dağılımı sabit etkiler modeline göre homojen özellik göstermektedir. Yani dağılımın homojen yapıya sahip olduğu söylenebilir. Dolayısıyla ders türüne göre oluşan gruplar arası etki büyüklükleri $\left(\mathrm{Q}_{\mathrm{B}}=\right.$ 1,183, p=0,00) açısından anlamlı bir farklılık olduğu söylenebilir.

\section{Etkililiği}

Çokkültürlü Eğitimin Çalışmanın Yapıldığı Ülkelere Göre

Çokkültürlü eğitimin etki büyüklüğünün çalışmanın yapıldığı ülkelere göre farklılaşıp farklılaşmadığını belirlemek için çalışmalar ABD ve Türkiye olmak üzere 2 gruba ayrılmıştır. Diğer yılların etki büyüklügü için yeterli sayıda olmamasından dolayı Tablo 3 'te yer verilmemiştir. Verilen 2 ülkenin analiz sonuçları Tablo $4^{\prime}$ te gösterilmiştir. 
Tablo 4. Çalışmaların Yapıldığı Ülkelere Göre Homojenlik Değerleri ve Etki Büyüklükleri

\begin{tabular}{|c|c|c|c|c|c|}
\hline \multirow{2}{*}{$\begin{array}{l}\text { Model } \\
\text { Türü }\end{array}$} & \multirow{2}{*}{$\begin{array}{l}\text { Gruplar arası Etki } \\
\text { Büyüklüğğu }\left(Q_{в}\right)\end{array}$} & \multirow[t]{2}{*}{$\mathbf{N}$} & \multirow[t]{2}{*}{ ES } & \multicolumn{2}{|c|}{$\begin{array}{c}\text { Etki Büyüklü̈̆̈ü } \\
\text { İçin \%95 Güven } \\
\text { Aralığı }\end{array}$} \\
\hline & & & & Alt Sinir & $\begin{array}{r}\text { Üst } \\
\text { Sin11 }\end{array}$ \\
\hline Ülkeler & 0,760 & & & & \\
\hline ABD & & 12 & 0,394 & 0,247 & 0,540 \\
\hline Türkiye & & 2 & 0,425 & 0,072 & 0,703 \\
\hline
\end{tabular}

Tablo 4'e göre, çalışmaların yapıldığı ülkelere göre yüksek etki büyüklügü 0,425 ile Türkiye, düşük etki büyüklüğü ise 0,394 ile ABD'ye aittir. Homojenlik testi sonucunda $Q$ istatistik değeri 0,760 olarak hesaplanmıştır. $X^{2}$ tablosundan $\% 95$ anlamlılık düzeyinde 1 serbestlik derecesi 0,00 bulunmuştur. Yani $Q$ istatistiksel değeri $(0,760)$, ki-kare dağılımının kritik değerinden $\left(x^{2}(0.95)=0,00\right)$ büyük çıktığı için çalışmaların yıllara göre dağılımı sabit etkiler modeline göre heterojen özellik göstermektedir. Yani dağılımın heterojen yapıya sahip olduğu söylenebilir.

\section{Çokkültürlü Eğitimin Bölüme Göre Etkililiği}

Çokkültürlü eğitimin etki büyüklüğünün çalışmanın yapıldığı bölüme göre farklılaşıp farklılaşmadığını belirlemek için çalışmalar psikoloji, rehberlik, ortaokul ve eğitim fakültesi olmak üzere 4 gruba ayrılmıştır. Diğer bölümlerin, etki büyüklüğü için yeterli sayıda olmamasından dolayı Tablo 5 'te yer verilmemiştir. Verilen dört bölümün analiz sonuçları Tablo 5'te gösterilmiştir. 
Tablo 5. Çalışmaların Yapıldığı Bölüme Göre Homojenlik Değerleri ve Etki Büyüklükleri

\begin{tabular}{|c|c|c|c|c|c|}
\hline \multirow{2}{*}{ Model Türü } & \multirow{2}{*}{$\begin{array}{c}\text { Gruplar arası } \\
\text { Etki Büyüklüğü } \\
\left(Q_{\text {в }}\right)\end{array}$} & \multirow{2}{*}{$\mathbf{N}$} & \multirow{2}{*}{ ES } & \multicolumn{2}{|c|}{$\begin{array}{l}\text { Etki Büyüklüğü İçin } \\
\text { \%95 Güven Aralığı }\end{array}$} \\
\hline & & & & Alt Sinur & Üst Sinur \\
\hline Bölümler & 0,589 & & & & \\
\hline Psikoloji & & 5 & 0,436 & 0,205 & 0,667 \\
\hline Rehberlik & & 2 & 1,100 & 0,709 & 1,490 \\
\hline $\begin{array}{l}\text { Eğitim } \\
\text { Fakültesi }\end{array}$ & & 2 & 0,257 & $-0,028$ & 0,543 \\
\hline Ortaokul & & 2 & 0,406 & 0,001 & 0,820 \\
\hline
\end{tabular}

Tablo 5'e göre, çalışmaların yapıldığı bölümlere göre en yüksek etki büyüklüğü 1,100 ile Rehberlik, en düşük etki büyüklüğü ise 0,257 ile Eğitim Fakültesi'ne aittir. Homojenlik testi sonucunda $Q$ istatistik değeri 0,589 olarak hesaplanmıştır. $X^{2}$ tablosundan $\% 95$ anlamlılık düzeyinde 3 serbestlik derecesi 41,731 bulunmuştur. Yani $Q$ istatistiksel değeri $(0,589)$, ki-kare dağılımının kritik değerinden $\left(x^{2}(0.95)=41,731\right)$ küçük çıktığı için çalışmaların yıllara göre dağılımı sabit etkiler modeline göre homojen özellik göstermektedir. Yani dağılımın homojen yapıya sahip olduğu söylenebilir. Dolayısıyla bölüm türüne göre oluşan gruplar arası etki büyüklükleri $\left(\mathrm{Q}_{B}=\right.$ $0,589, p=0,161$ ) açısından anlamlı bir farklılık olmadığı söylenebilir.

\section{Çokkültürlü Eğitimin Öğrenim Düzeyine Göre Etkililiği}

Çokkültürlü eğitimin etki büyüklüğünün çalışmanın yapıldığı öğrenim düzeyine göre farklılaşıp farklılaşmadığını belirlemek için çalışmalar ortaokul, lisans ve yüksek lisans olmak üzere 3 gruba ayrılmıştır. Diğer bölümlerin, etki büyüklüğü için yeterli sayıda olmamasından dolayı Tablo 6'da yer verilmemiştir. Verilen 3 öğrenim düzeyinin analiz sonuçları Tablo 6'da gösterilmiştir. 
Tablo 6. Çalışmaların Yapıldığı Öğrenim Düzeyine Göre Homojenlik Değerleri ve Etki Büyüklükleri

\begin{tabular}{|c|c|c|c|c|c|}
\hline \multirow{2}{*}{ Model Türü } & \multirow{2}{*}{$\begin{array}{l}\text { Gruplar arası } \\
\text { Etki } \\
\text { Büyüklüŭğü } \\
\left(Q_{B}\right)\end{array}$} & \multirow{2}{*}{$\mathbf{N}$} & \multirow{2}{*}{ ES } & \multicolumn{2}{|c|}{$\begin{array}{l}\text { Etki Büyüklü̈̆̈̈ İçin } \\
\text { \%95 Güven Aralığ1 }\end{array}$} \\
\hline & & & & Alt Sinir & Üst Sinır \\
\hline Öğrenim & & & & & \\
\hline Düzeyi & 0,228 & & & & \\
\hline Ortaokul & & 2 & $-0,342$ & $-0,756$ & 0,072 \\
\hline Lisans & & 10 & 0,469 & 0,309 & 0,629 \\
\hline Yüksek Lisans & & 2 & 0,226 & $-0,014$ & 0,466 \\
\hline
\end{tabular}

Tablo 6'ya göre, çalışmaların yapıldığı öğrenim düzeyine göre en yüksek etki büyüklüğü 0,469 ile lisans, en düşük etki büyüklüğü ise $-0,342$ ile ortaokul düzeyine aittir. Homojenlik testi sonucunda $\mathrm{Q}$ istatistik değeri 0,228 olarak hesaplanmıştır. $X^{2}$ tablosundan \%95 anlamlılık düzeyinde 2 serbestlik derecesi 86,157 bulunmuştur. Yani Q istatistiksel değeri $(0,228)$, kikare dağılımının kritik değerinden $\left(x^{2}(0.95)=86,157\right)$ küçük çıktığ1 için çalışmaların yıllara göre dağılımı sabit etkiler modeline göre homojen özellik göstermektedir. Yani dağılımın homojen yapıya sahip olduğu söylenebilir. Dolayısıyla öğrenim düzeyine göre oluşan gruplar arası etki büyüklükleri $\left(\mathrm{Q}_{B}=0,228, \mathrm{p}=0,00\right)$ açısından anlamlı bir farklılık olduğu söylenebilir.

Çokkültürlü Eğitimin Çalışmanın Yapıldığı Süreye Göre Etkililiği

Çokkültürlü eğitimin etki büyüklüğünün çalışmanın yapıldığı süreye göre farklılaşıp farklılaşmadığını belirlemek için çalışmalar 5 hafta ve 1 dönem olmak üzere 2 gruba ayrılmıştır. Diğer bölümlerin, etki büyüklüğü için yeterli sayıda olmamasından dolayı Tablo $7^{\prime}$ de yer verilmemiştir. Verilen iki öğrenim sürelerinin analiz sonuçları Tablo 7 ' de gösterilmiştir. 
Tablo 7. Çalışmaların Yapıldığı Süreye Göre Homojenlik Değerleri ve Etki Büyüklükleri

\begin{tabular}{|c|c|c|c|c|c|}
\hline \multirow[t]{2}{*}{$\begin{array}{l}\text { Model } \\
\text { Türü }\end{array}$} & \multirow[t]{2}{*}{$\begin{array}{l}\text { Gruplar arası Etki } \\
\text { Büyükklüğ̈̈ }\left(Q_{B}\right)\end{array}$} & \multirow[t]{2}{*}{$\mathbf{N}$} & \multirow[t]{2}{*}{ ES } & \multicolumn{2}{|c|}{$\begin{array}{c}\text { Etki Büyüklüğg̈ } \\
\text { İçin \%95 Güven } \\
\text { Aralığı }\end{array}$} \\
\hline & & & & Alt Sinir & Üst Sinır \\
\hline Süre & 0,728 & & & & \\
\hline 5 hafta & & 2 & 0,324 & $-0,079$ & 0,727 \\
\hline 1 dönem & & 7 & 0,420 & 0,240 & 0,600 \\
\hline
\end{tabular}

Tablo 7'ye göre, çalı̧̧maların yapıldığı öğrenim süresine göre yüksek etki büyüklüğü 0,420 ile 1 dönem, düşük etki büyüklüğü ise 0,324 ile 5 hafta uygulanan çalışmalara aittir. Homojenlik testi sonucunda Q istatistik değeri 0,728 olarak hesaplanmıştır. $X^{2}$ tablosundan \%95 anlamlılık düzeyinde 1 serbestlik derecesi 0,000 bulunmuştur. Yani $Q$ istatistiksel değeri $(0,728)$, ki-kare dağılımının kritik değerinden $\left(x^{2}(0.95)=0,000\right)$ büyük çıktığı için çalışmaların yıllara göre dağılımı sabit etkiler modeline göre heterojen özellik göstermektedir. Yani dağılımın heterojen yapıya sahip olduğu söylenebilir. Dolayısıyla öğrenim düzeyine göre oluşan gruplar arası etki büyüklükleri $\left(\mathrm{Q}_{\mathrm{B}}=0,728, \mathrm{p}=0,465\right)$ açısından anlamlı bir farklılık olmadığı söylenebilir.

\section{Tartışma, Sonuç ve Öneriler}

Çokkültürlü eğitim yaklaşımının akademik başarı düzeylerine ilişkin etki büyüklügünü belirlemeyi amaçlayan bu meta-analize 17 araştırma dâhil edilmiştir. Bu araştırmalara ait en yüksek katılım, 2013 yılına aittir. Çalışmalar daha çok Amerika'da $(\mathrm{n}=12)$ yapılmış ve uygulama süresi açısından araştırmalarda bir akademik dönem tercih edilmiştir. Bölüm açısından ele alındığında ise çalışmaların büyük bir kısmı lisans seviyesinde psikoloji bölümünde yapılmıştır. 1245 kişilik örneklemi oluşturan 17 çalışmaya ait 33 adet etki büyüklüğü hesaplanmıştır. Bu 17 çalışma üzerinde, çalışmanın yapıldığı yıllara göre ve öğrenim düzeyine ve ülkelere göre anlamlı farklılık bulunurken; çalışmanın yapıldığı bölüm ve araştırma sürelerine göre anlamlı farklılığın bulunmadığı sonucuna varılmıştır. Eldeki çalışma Gözüyeşil \& Dikici (2014) tarafından yapılan beyin temelli öğrenmenin akademik başarıya etkisinin incelendiği meta-analiz çalışma ile paralellik göstermektedir. Adı geçen çalışmada etki büyüklükleri öğrenim 
düzeyi, ders alanı ve örneklem sayısına göre farklılaşmamış olarak bulunmuştur.

Araştırmadan elde edilen verilere göre, çokkültürlü eğitim yaklaşımı lehine etki büyüklüğü $\mathrm{ES}=0,650$ olarak bulunmuştur. Bu araştırma için belirlenen ölçütlere göre, iki ve üzeri çalışma yapılan ülkelerde; Avusturya, Güney Kore, Tayvan, Türkiye ve Amerika'da çokkültürlü eğitim üzerine yapılan 17 çalışmanın Cohen'in (2013) sınıflaması çerçevesinde uygulanan çokkültürlü eğitimin akademik başarıya etkisinin olduğu ve orta düzeyde $(0.40<$ Cohen's $d<0.75)$ olduğu söylenebilir. Bu sonuç alanyazında ulusal ve uluslar arası farklı yıllarda yapılan birçok araştırmayla tutarlılık göstermektedir (Adeeb, 1994; Bernstein, Zimmerman, Werner-Wilson \& Vosburg, 2000; Eisenberg vd., 2013; Kağnıc1, 2011; Soble, Spanierman \& Liao, 2010). Ancak homojenlik testi sonucunda çalışmaların heterojen çıkması verilerin evrene genellenemeyeceğini göstermektedir. Dolayısıyla heterojenliği artıran etmenler; örneklem hatası veya araştırılan değişkenler dışında başka değişkenlerin de deney grubunu etkilemiş olduğu söylenebilir.

Eldeki meta-analiz çalışmasında, çalışmanın yapıldığı yıllara, ülkelere, bölümlere, öğrenim düzeylerine ve araştırma sürelerine göre etki büyüklüklerinin farklılaşıp farklılaşmadığı da analiz edilmiştir. Çalışmaların yapıldığı yıllara göre; 2010, 2011 ve 2013 olmak üzere 3 farklı grup üzerinde etki büyüklüğü analiz edilmiştir. Bu yıllarda etki büyüklüklerinin pozitif değer aldığı görülmüştür. Yıllar açısından en yüksek etki büyüklüğü 2013, en düşük etki büyüklüğü ise 2010 yılında olduğu görülmüştür. Meta-analize dâhil edilen çalışmaların yıllara göre oluşan gruplar arası etki büyüklüklerine $\left(\mathrm{Q}_{\mathrm{B}}=1,183, \mathrm{p}=0,000\right)$ bakıldığında anlamlı bir farklılık olduğu söylenebilir. Diğer bir ifadeyle geçen süreyle birlikte araştırma sayısının artmasına bağlı olarak etki büyüklüğünün arttığı söylenebilir.

Örneklemlerin öğrenim düzeyine göre meta-analiz yapıldı̆̆ında; varılan sonuçlara göre, en yüksek etki büyüklüğü 0,469 ile lisans düzeyinde, en düşük etki büyüklüğü ise $-0,342$ ile ortaokul düzeyinde gerçekleşmiştir. Meta-analize dâhil edilen çalışmaların öğrenim düzeyine göre oluşan gruplar arası etki büyüklüklerine $\left(\mathrm{Q}_{\mathrm{B}}=0,228, \mathrm{p}=0,000\right)$ bakıldığında anlamlı bir farklılık olduğu söylenebilir. Diğer bir ifadeyle çokkültürlü eğitim yaklaşımı ile yapılan derslerdeki akademik başarı öğrencilerin öğrenim düzeyine göre değişmektedir. Eldeki çalışma Kablan, Topan \& Erkan (2013) tarafından materyal kullanmanın akademik başarıya etkisi adlı çalışmasındaki sonuçlar ile çelişmektedir. Adı geçen çalışmada öğrenim düzeyine göre etkililik bulunmazken, bu araştırmada öğrenim düzeyinin 
başarıyı etkilediği bulunmuştur. Ortaokul düzeyi hariç diğer kategorilerde etki büyüklüğü pozitif değer almıştır. Ortaokul düzeyi çalışmaların iki çalışmayla sınırlı olmasından dolayı, etki büyüklüğü değerinin tüm ortaokul grubuna genellenemeyeceği söylenebilir.

Ülkelere göre analiz yapıldığında; elde edilen sonuçlara göre, ölçütler çerçevesinde en az iki çalışmaya sahip ülkelerden; en yüksek etki büyüklügü $(0,425)$ ile Türkiye, en düşük etki büyüklüğü $(0,394)$ ile $A B D$ tespit edilmiştir. Buna göre, Türkiye ve $\mathrm{ABD}$ arasında karşılaştırma yapılmıştır. Meta-analize dâhil edilen çalışmaların ülkelere göre gruplandırıldığında ortaya çıkan etki büyüklüğüne göre $\left(\mathrm{Q}_{B}=0,760, \mathrm{p}=0,000\right)$ gruplar arasında anlamlı bir farklılık olduğu söylenebilir. Bu sonuç Gözüyeşil \& Dikici (2014) tarafından yapılan çalışmanın sonuçları ile benzer benzerdir.

Çalışmanın yapıldığı bölüme göre, en yüksek etki büyüklüğü 1,100 ile Rehberlik, en düşük etki büyüklüğü ise 0,257 ile Eğitim Fakültesi'ne aittir. Bölüm türüne göre oluşan gruplar arası etki büyüklükleri $\left(\mathrm{Q}_{\mathrm{B}}=0,589\right.$, $\mathrm{p}=0,161$ ) açısından anlamlı bir farklılık olmadığı söylenebilir. Diğer taraftan çalışmaların yapıldığ öğrenim süresine göre yüksek etki büyüklüğü 0,420 ile 1 dönem, düşük etki büyüklüğü ise 0,324 ile 5 hafta uygulanan çalışmalara aittir. Dolayısıyla öğrenim düzeyine göre oluşan gruplar arası etki büyüklükleri $\left(\mathrm{Q}_{\text {в }}=0,728, \mathrm{p}=0,465\right)$ açısından anlamlı bir farklılık olmadığı söylenebilir. Görüldüğü üzere, çalışmanın yapıldığı bölümler ve araştırmanın uygulama sürelerine göre elde edilen verilerin sınıflandırılmasında homojen yapının bozulmadığı görülmektedir. Metaanalize bu kategorilerde dâhil edilen çalışmaların birbiri ile tutarlı olduğu söylenebilir. Diğer taraftan çalışmaların yapıldığı ülkelere ait verilerin analizde Türkiye ve ABD'ye ait çalışmaların heterojen yapıya sahip olduğu görülmüştür. $\mathrm{Bu}$ heterojenliğin veya istatistiksel farklılığın sebebinin; Türkiye'de yapılan çalışmaların sontest sonuçlarının elde edildiği testlerin olabileceği gibi, bu testlerin çoğunlukla deneyi yapan araştırmacı tarafından geliştirilen başarı testlerinin de olabileceği söylenebilir. Ayrıca ABD'de bu farklılı̆̆ın, yapılan çalışmaların çoğunlukla ulusal veya uluslararası standartlara göre düzenlenmiş geçerlik ve güvenirliğe sahip başarı testlerinden oluşması göz ardı edilmemelidir. Diğer bir taraftan, araştırmalardan elde edilen sonuçlara göre, deneysel çalışmanın sinırlılıklarından kaynaklı; deney grubunu başka bağımsız değişkenlerin etkilemiş̧ olabileceği varsayımı göz ardı edilmemelidir. Deneyi yapan araştırmacının tutumu ve önyargıları ve deney grubunun kontrol grubuna göre daha fazla olumlu etkide bırakılması araştırma sonuçlarını sadece çokkültürlü eğitim yaklaşımının akademik başarıyı doğrudan olumlu 
etkilediğine dair savda bulunmak eksik olabilir. Bu nedenle deneysel çalışmaların sınırlılıkları göz önünde bulundurularak deneysel çalışmaların yorumlanması gerekmektedir.

Yukarıda yapılan eleştiriler doğrultusunda uygulayıcılara bazı öneriler sunulmuştur. Bu meta-analiz çalışmasında çokkültürlü eğitim yaklaşımının öğrencilerin sadece akademik başarısına olan etkisi incelenmiştir. Bu konuda çalışma yapacak araştırmacıların çokkültürlü eğitim yaklaşımının tutum ve motivasyon gibi faktörler üzerine etkisi gibi farklı konularda meta-analiz çalışması gerçekleştirilebilir. Daha geniş kapsamlı meta-analiz çalışmaları gerçekleştirebilirler. Yani ülke sayısını artırarak meta analiz sonuçlarını karşılaştırabilirler. Ayrıca deneysel çalışmalarda araştırmacı kendi geliştirdiği testleri kullanmak yerine ulusal güvenirliliği ve geçerliliği olan testleri kullanması önerilebilir. Bunu dışında bu yaklaşım ile ilgili alanda yazılan çalışma sayısı çok olmamakla birlikte bu konuda yeni çalışmalar yapılabilir.

\section{Kaynakça}

Yıldız imi $\left({ }^{*}\right)$ ile işaretlenmiş kaynaklar, meta-analize dâhil edilen çalışmaları göstermektedir.

*Adams, E.A.,Waldo, M., Steiner, R.,Mayfield, R., Ackerlind, S.J. \& Castellanos, L.P. (2003). Creating Peace by Confronting Prejudice: Examining the Effects of a Multicultural Communication Skills Group Intervention. International Journal for the Advancement of Counselling, 25(4), 281-291.

*Adeeb, P.M. (1994). A Quasi-Experimental Design To Study The Effect of Multicultural Coursework And Culturally Diverse Field Placements On Preservice Teachers' Attitudes Toward Diversity. (Unpublished Doctoral Theses). University Of North Florida/ College Of Education And Human Services, Jacksonville/ Florida.

Ameny-Dixon, G. M. (2004). Why multicultural education is more important in higher education now than ever: A global perspective. International Journal of Scholarly Academic Intellectual Diversity, 8(1), 19.

*Arizaga, M., Bauman, S., Waldo, M. \& Castellanos, L.P. (2005). Multicultural Sensitivity And Interpersonal Skills Training For Preservice Teachers. Journal Of Humanistic Counselıng, Educatıon And Developmet, 44, 198-208. 
Aydin, H. (2013). A Literature-based Approaches on Multicultural Education. The Journal of Anthropologist. 16 (2), 31-44.

Banks, J. A. (1993). Multicultural Education: Historical Develelopment, Dimensions, and Practice. Review of Research in Education, 19, 3-49.

Banks, J. A. (2008). An Introduction to Multicultural Education. Prentice Hall: Pearson Publication.

Banks, J.A., \& Banks, C.A.M. (2001). Multicultural Education: Issues and Perspectives. 4th Edition. New York, NY: John Wiley and Sons, Inc.

Başbay, A., \& Kağnıcı D.Y. (2011). Çok Kültürlü Yeterlik Algıları Ölçeği: Bir Ölçek Geliştirme Çalışması. Eğitim ve Bilim, 36 (161), 199-212.

Bennett, C. (2003). Comprehensive Multicultural Education: Theory and Practice. Boston, MA: Pearson Education Inc.

Bennett, C. (2011). Genres of Research in Multicultural Education. Review of Educational Research, 71(2), 171-217.

*Bernstein, J., Zimmerman, T.S., Werner-Wilson, R.J. \& Vosburg, J. (2000). Preschool Children's Classification Skills and a Multicultural Education Intervention To Promote Acceptance of Ethnic Diversity. Journal of Research in Childhood Education, 14(2),181-192.

Bucher, R. D. (2009). Diversity Consciousness. Opening Our Minds to People, Cultures, and Opportunities (3th Edition). Prentice Hall: Pearson Publication.

*Bui, Y.N., \& Fagan, Y.M. (2013). The Effects of an Integrated Reading Comprehension Strategy: A Culturally Responsive Teaching Approach for Fifth-Grade Students' Reading Comprehension, Preventing School Failure: Alternative Education for Children and Youth, 57(2), 59-69, DOI: 10.1080/1045988X.2012.664581

Clark, C., \& Gorski, P. (2002). Multicultural education and the digital divide: Focus on socio-economic class background. Multicultural Perspectives, 4(3), 25-36.

Cohen, J. (2013). Statistical power analysis for the behavioral sciences. Hillsdale, NJ: Lawrence Erlbaum Associates.

*Eisenberg, J., Lee, H., Brück, F., Brenner, B., Claes, M., Mironski, J. \& Bell, R. (2013). Can Business Schools Make Students Culturally Competent? Effects of Cross- Cultural Management Courses on Cultural Intelligence. Academy of Management Learning \& Education, 12 (4), 603-621.

Ellis, P. D. (2012). The essential guide to effect sizes (5th edition). CambridgeUK: Cambridge University Press. 
*Estrada, A.U., Durlak, J.A. \& Juarez, S.C. (2002). Developing Multicultural Counseling Competencies in Undergraduate Students. Journal of Multicultural Counseling And Development, 30, 110-123.

Gay, G. (2004). The Importance of Multicultural Education. Educational Leadership, December 2003, January 2004. 30-35.

Glass, G. V., McGaw, B., \& Smith, M. L. (2012). Meta-analysis in social research.Beverly Hills, CA: Sage.

Gözüyeşil, E., \& Dikici, A. (2014). Beyin temelli öğrenmenin akademik başarıya etkisi: Bir meta-analiz çalışması. Educational Sciences: Theory E Practice, 14(2), 1-2. DOI: 10.12738/estp.2014.2.2103

*Ho, M.J., Yao, G., Lee, K.L., Beach, M.C. \& Green, A.R. (2008). CrossCultural Medical Education: Can Patientcentered Cultural Competency Training Be Effective In Non-Western Countries? Medical Reacher, 30, 719-721, DOI: 10.1080/01421590802232842.

Hedges, L. V., \& Olkin, I. (1985). Vote-counting methods in research synthesis. Psychological Bulletin, 88, 359-369.

Hunter, J. E., \& Schmidt, F. L. (2004). Methods of meta-analysis: Correcting error and bias in research findings (2nd ed.). California: Sage.

*Ikehara, A. (2001). The Effect Of An Introduction To Okinawan Music On Students' Attitudinal Statements Regarding Multicultural Music Education And People From Other Cultures. Missouri Journal Of Research in Music Education, 38, 30-44.

Johnson, D. W., \& Johnson, R.T. (2002). Multicultural education and human relations: Valuing diversity. Boston M.A: Allyn Bacon.

Kablan, Z., Topan, B., \& Erkan, B. (2013). Sınıf İçi Öğretimde Materyal Kullanımının Etkililik Düzeyi: Bir Meta-Analiz Çalışması. Educational Sciences: Theory \& Practice, 13(3), 1629-1644. DOI: 10.12738/estp.2013.3.1692

*Kağnıcı, D.Y. (2011). Teaching Multicultural Counseling: An Example From Turkish Counseling Undergraduate Program. Eurasian Journal of Educational Research, 44, 111-128.

*Larsen, R., \& Reif, L.A. (2011). Effectiveness of Cultural Immersion and Culture Classes for Enhancing Nursing Students'Transcultural SelfEfficacy. Journal of Nursing Education,50 (6), 350-354.

*Lee, E.O., Brown, M. \& Bertera, E.M. (2010). The Use of an Online Diversity Forum to Facilitate Social Work Students' Dialogue on Sensitive Issues: A Quasi-Experimental Design. Journal of Teaching in Social Work, 30, 272-287, DOI:10.1080/08841233.2010.499066 
National Association of Multicultural Education, (NAME). (2012). Multicultural Education. From http://nameorg.org/names mission/definition-ofmulticultural education/ (Retrieved on May 29, 2014).

Nieto, S. (2010). The Light in Theirs Eyes: Creating Multicultural Learning Communities. 10th Edition. New York, NY: Teachers College Press.

Nieto, S., \& Bode, P. (2011). Affirming Diversity: The Sociopolitical Context of Multicultural Education. 6th Edition. Boston, MA: Pearson Education Inc.

*Peek, E.H., \& Park, C.S. (2013). Effects of a Multicultural Education Program on the Cultural Competence, Empathy and Self-efficacy of Nursing Students. J Korean Acad Nurs, 43 (5), 690-696.

*Pedersen, P.J. (2010). Assessing İntercultural Effectiveness Outcomes in a Year-Long Study Abroad Program. International Journal Of Intercultural Relations, 34, 70-80.

Petticrew, M., \& Roberts, H. (2006). Systematic reviews in the social sciences. MA-USA: Blackwell Publishers Ltd.

Smith, T., Constantine, M. G., Dunn, T. W., Dinehart, J. M. \& Montoya, J. A. (2006). Multicultural Education in the Mental health Professions: AMeta-Analytic Review. Journal of Counseling Psychology, 53 (1), 132145.

*Soble, J.R., Spanierman, L.B. \& Liao, H.Y. (2010). Effects of a Brief Video Intervention on White University Students' Racial Attitudes. Journal of Counseling Psychology. 58 (1), 151-157. DOI: 10.1037/a0021158

*Şahin, A., Çelik, T. \& Bilgen, N. (2013). Effect of Media Literacy on Prospective Social Studies Teachers' Multicultural Attitudes. International Online Journal of Educational Sciences, 5 (3), 520-530.

*Wang, V.O. (1998). Curriculum Evaluation and Assessment of Multicultural Genetic Counselor Education. Journal of Genetic Counseling, 7(1), 87111.

Wilson, K. (2012). Multicultural Education. From $<$ http://www.edchange.org/multicultural/apers/keith.html> (Retrieved May on 28, 2014).

Wolf, F. M. (1986). Meta-analysis: Quantitative methods for research synthesis. Beverly Hills, CA: Sage.

Zachary, John. (2014). Dani Alves Eats Banana Thrown From Crowd. $<$ http://guardianlv.com/2014/04/dani-alves-eats-banana-thrownfrom-crowd/\#HshSHfphTAZXPIgs.99.> ((Retrieved May on 05, 2014). 
\begin{tabular}{l|l} 
R. GÜNAY, Y. KAYA, H. AYDIN & 166
\end{tabular} 